Short Report

\title{
Impact of the Coronavirus Pandemic on the Education and School System at a Large School in the Nations' Least Affluent Congressional District and Around the World
}

Eugene Stephane Mananga ${ }^{1,2,3,{ }^{*} \text {, Lamisa Rusmeha } 4}$

1. The Graduate Center, The City University of New York, 365 Fifth Avenue, New York, NY, 10016, USA; E-Mail: emananga@gradcenter.cuny.edu

2. Department of Engineering, Physics, and Technology, Bronx Community College, The City University of New York, 2155 University Avenue, Bronx, NY 10453, USA; E-Mail: eugene.mananga@bcc.cuny.edu

3. Department of Applied Physics, New York University, 6 Metro-tech Center, Brooklyn, New York 11201, USA; E-Mail: eugene.mananga@nyu.edu

4. Department of Chemistry, Hunter College,695 Park Ave, New York, NY 10065; E-Mail: lamisa.rusmeha76@myhunter.cuny.edu

* Correspondence: Eugene Stephane Mananga; E-Mails: esm041@mail.harvard.edu; emananga@gradcenter.cuny.edu

Academic Editor: Gerhard Litscher

OBM Integrative and Complementary Medicine

2021, volume 6 , issue 2

doi:10.21926/obm.icm.2102012
Received: December 23, 2020

Accepted: April 01, 2021

Published: April 13, 2021

Towards the end of 2019, an unanticipated outbreak, coronavirus also referred to as COVID-19's first cases occurred in Wuhan City, Hubei Province, China. In early 2020, the World Health Organization (WHO) declared the pandemic as a Public Health emergency of international concern. COVID-19 is a transmissible disease caused by severe acute respiratory syndrome coronavirus 2 (SARS-CoV-2) [1]. The COVID-19 puts a spotlight on numerous issues varying from educational, social, political, and economic that were already present before the pandemic. Hence, in this short report, we present the severe impact of the COVID-19 pandemic on a broader scale across the

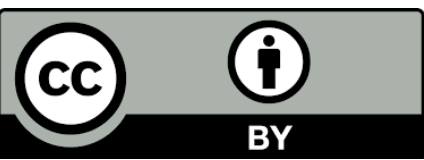

(C) 2021 by the author. This is an open access article distributed under the conditions of the Creative Commons by Attribution License, which permits unrestricted use, distribution, and reproduction in any medium or format, provided the original work is correctly cited. 
educational system at Bronx Community College (BCC) of the City University of New York (CUNY) and throughout the world, affecting nearly 1.6 billion learners in more than 200 countries [2].

Located in the South Bronx, BCC sits in the nation's poorest Congressional District, CD 15 [3]. Here, $34.2 \%$ of residents live below poverty levels, vs. $12.7 \%$ nationwide. Approximately $88 \%$ of $\mathrm{BCC}$ students receive financial aid to attend the college, which offers associate degrees in more than 60 disciplines as well as certificate programs. Current enrollment is about 10,500 with approximately $90 \%$ of the student population of Hispanic and Black/African descent. Students hail from more than 100 countries and speak 24 different languages. BCC is a federally designated Hispanic-serving institution where $53 \%$ of the student body are first-generation college students. For instance, the number of Black/African descent students that earned an Associate Degree in physical sciences from BCC in the 2016-2017 academic year is less than $25 \%$ of the total number of Hispanic and White. Surprisingly, since the 2010-2011 academic year, this rate has never exceeded $30 \%$. In 2016-2017, the rates for students of Black/African descent earning a doctorate degree in physical sciences at the Graduate Center of CUNY are between $2 \%$ and $8 \%$. BCC's student enrollment in 2018 consists of $61 \%$ Hispanics, 33\% Black/African descent, 4\% Asians, and $2 \%$ White. However, at the doctorate student level at the Graduate Center of CUNY, the rate of students' enrollment in 2016 becomes 8\% Black/African descent, 15\% Hispanics, 9\% Asians, and 65\% White. The limitation of Black students in higher education, science, technology, engineering, and mathematics (STEM) is apparent and petrifying. This disadvantage is also obvious in the Hispanic and women students [4]. The first author truly believes that, the years spent as an undergraduate student are among the most formative. For this reason, undergraduate students need to be not only equipped with scientific knowledge but also mentored. As a result, they can take full advantage of the opportunities that exist during and after their college years. The COVID-19 pandemic made an unprecedented impact at BCC, CUNY, and globally. To help contain the spread of the disease, schools around the world had been closed, immensely affecting the education system worldwide.

The Education and school system in the United States have been among the most important and affected sectors by the pandemic of COVID-19. The World Health Organization declared the COVID19 a global pandemic in March 2020 with two hundred thousand confirmed cases of infected patients and a death toll surpassing more than eight thousand deaths across over hundred and sixty countries. It emerged as a great crisis in all areas of life across the world [5]. In early spring, as the pandemic was hitting its first peak, the virus consigned nearly over 55 million school children in the United States under the age of 18 to stay in their homes, with 1.4 billion out of school or child care across the globe $[6,7]$. Students were affected from all economic background at BCC of CUNY and in the United States as well as around the world. The pandemic greatly impacted the school and education system by converting the traditional method of in-person learning to virtual learning, enabling students and teachers to attend class at the comfort of their home, which limits the risk of COVID-19 infection. Mishra and co-workers [8] recently presented a study for the Mizoram University in India on online teaching-learning in higher education during lockdown period of COVID-19 pandemic. The paper draws a holistic picture of ongoing online teaching-learning activities during the lockdown period including establishing the linkage between change management process and online teaching-learning process in the education system amid the COVID-19 outbreak. Mishra's paper employs both quantitative and qualitative approach to study the perceptions of teachers and students on online teaching-learning modes. It also highlighted the implementation process of online teaching-learning modes [8]. This analysis concludes that the 
governments must ensure the availability of reliable communication tools, high quality digital academic experience, and promote technology-enabled learning for students to bridge the disparities originated in the education system before and after the COVID-19 catastrophe which is also inevitably necessary for uninterrupted learning [8]. Several recent published articles such as the work by Aucejo and co-workers discussed also student's mental wellbeing issue [8, 9].

Aucejo and co-workers investigated the impact of COVID-19 on student's experiences and expectations. Their work shows that the economic and health related shocks induced by COVID-19 vary systematically by socioeconomic factors and constitute key mediators in explaining the pandemic's significant effects. Aucejo's analysis provides the first systematic analysis of the effects of COVID-19 on higher education. In a survey of 1500 students at Arizona State University, Aucejo and co-workers performed a quantitative evidence that shows the pandemic's adverse effects on students' outcomes and expectations. Aucejo found that $13 \%$ of students have delayed graduation due to COVID-19. Expanding upon these results, Aucejo showed that the pandemic's effects are highly heterogeneous. Lower-income students are 55\% more likely to delay graduation compared to their higher-income counterparts. The closure of schools and other learning spaces has impacted 94\% of the world's student population, up to $99 \%$ in low and lower-middle income countries around the world [10]. The transition of the education system from in person to virtual setting has been beneficial to students who have access to technology, while disruptive for the students belonging from low socio-economic background [11, 12].

The rise of virtual education has raised many questions among the learners and instructors about this learning method's efficacy. Virtual education can have many beneficial effects on the lives of most students and as well as the instructors. When one reflects on the traditional education system, the first thing that strikes in mind is attending classes in a room packed with students. However, after the COVID-19, the idea of acquiring education has forcefully transformed into attending classes virtually. One can argue that this transition from in-person to online class has shown effective results in diminishing whilst combating the spread of COVID-19. It has indeed been very effective in plummeting the spread, but also it has opened a new dawn to the educational system. Worth mentioning is that one out of the many favorable long-term effects of the virtual education system is that it has enabled students to attend classes from the comfort of their homes from any part of the world. The studies by Marteney and co-workers, and Paudel show that online education has made easier for students with limitations to access learning activities. Improvements have been made in student academic performance and students have had success with asynchronous education. Furthermore, student motivation has increased, and more individualized support has been available $[13,14]$. While on the other hand, the teachers have the freedom to personalize instruction methods depending on the student's needs, the students have become effective learners through this process. The work by Duraku and Hoxha [15] states that teachers' perspectives on teaching methodology have been proven to influence the level of technology integration in the classroom and have significantly increased students' participation in class. In addition, virtual education has minimized the travelling time that was required for attending face-to-face classes. The surveys by Muthuprasad and co-workers reveal that virtual education has equipped students with great flexibility and convenience while acquiring education and learning in a self-paced method [16]. Since technology and the world at large are constantly upgrading, virtual education undoubtedly equips students for their future work environments. Hence, there are many positive impacts of virtual education if the learning methods are executed properly [17]. 
COVID-19 pandemic was an unexpected and abrupt pandemic resulting in a sudden transition from the traditional learning method to the virtual education system. This transition had to be implemented with immediate effect. Indeed, some hurdles have also been detected, especially for aged instructors and as well as students of low socio-economic backgrounds. Online education may demonstrate some positive aspects, but it may also have some drawbacks as highlighted by Hebebci and co-workers. Hebebci, Bertiz, \& Alan [18] find that teachers and students had both positive and negative attitudes towards online education whereas Serhan [19] finds that students had a negative attitude to the use of video conferencing tools. The proper transition process from in-person education to virtual education requires induction and familiarization for both the students and the instructors. But due to COVID-19 pandemic, there wasn't an adequate time frame for training for a smooth transition to transpire. However, if it was provided, it could have been a revolutionary change in the education system and might have resulted in the permanent elimination of in-person education [20]. The massive scale of school closures had laid bare the uneven distribution of the technology needed to facilitate remote learning. Recently, Barbour highlighted the lack of preparedness and low resilience of systems to support teachers, facilitators, and parents in the successful and safe use of technology for learning [21]. Earlier research found that students working offline were learning with more efficacy compared to students learning virtually [22]. The COVID19 pandemic has caused the whole educational system from elementary to tertiary level to collapse during the lockdown period of the novel coronavirus disease across the globe [8]. Even though the primary motive of school is to educate students, it also gives students an invaluable ample opportunity to encounter and befriend students from diverse cultural and ethnic backgrounds. But as a result of virtual education, it has disrupted the social interactions of students and created harmful effects on the mental health of the students. Virtual education also requires academically capable, motivated and independent learners, which sometimes makes it hard for certain students to acquire information through virtual education due to lacking such traits [21]. The research on online education shows that students displayed a wide range of responses, with most expressing anxiety toward online learning, disappointment regarding graduation ceremony, and online learning being different than standard in-class learning [23]. According to Aucejo and co-workers $[9,24]$ COVID-19 has been the cause of $13 \%$ of students having delayed graduation, $40 \%$ have losing a job, internship, or job offer, and $29 \%$ expecting to earn less at age 35 . Moreover, these effects have been highly heterogeneous. One quarter of students increased their study time by more than 4 hours per week due to COVID-19, while another quarter decreased their study time by more than 5 hours per week. This heterogeneity often followed existing socioeconomic divides. Lower-income students are $55 \%$ more likely than their higher-income peers to have delayed graduation due to COVID-19. Therefore, the immediate transition from in-person education to virtual education has negatively impacted both the students and the instructors from all points of life, especially the students physical and mental health.

Virtual education has affected the students' mental health due to uncertainty about their exams, internships, jobs and graduation [25]. When students were interviewed about their experience with virtual education, they expressed that disruptions during schooling and feelings of social isolation were their main concerns. For most students who used to study in school/college library, are now confined within a room if of course, they come from a well-off family. Worth noting, in 2019, the poverty rate in NY State was at $13 \%$, making it difficult for most college students in New York State to even afford a room where they can live or study by themselves. Sitting down in front of a 
computer for prolonged periods can also result in numerous harmful health complications, such as back pain, migraines and dry eyes, just to name a few to both students and teachers [26-28].

Due to many families being unable to afford a high-quality stable internet connection, many students suffer from anxiety and stress over internet disconnection during a test or doing homework. Researchers have also investigated the extent to which components of virtual education enhance learning. While learning in a virtual setting, students were not able to establish as much trust in their virtual instructors compared to a traditional setting, which also disrupted the process of learning efficiently. Thus, there are many components of virtual education that haven't been quite effective for students to acquire knowledge in the fast transition of education methods due to COVID-19 [29-31].

Online learning at first was practiced as a contingent solution to keep the education ongoing. However, the students recognized the impacts of online learning such as having more extra-time for self-study, exposing to new and interesting forms of learning, and having easy access to resourceful materials online [17]. Although there are certain drawbacks of virtual education, these challenges can be resolved with proper training and practical guidelines keeping the students physical while cognitive health in mind. A survey on virtual students' mental health showed that more than half of the participants have mental health scores that lie below a threshold, indicative of major depression. The data suggest that supplementing psychosocial support to students can enhance their quality and remote learning experience [32]. Any student experiencing feelings of heightened anxiety about COVID-19 should be provided with proper psychological support [33]. Consequently, the transition from traditional to the virtual education system due to COVID-19 has created countless unfortunate complications for teachers and students, but moreover to the students' mental health due to a lack of interaction with their peers and prolonged exposure to computers. However, some instructors managed well, while others struggled [34]. Daumiller and co-worker recently elucidated interindividual differences in online teaching and learning during this pandemic circumstance. Daumiller analyzed longitudinal data of 80 faculty members' achievement goals during the semester prior to shifting to online teaching, as well as their attitudes and burnout or engagement during the first semester with enforced online teaching. Next, the analysis of 703 student ratings of these faculty members' teaching quality was performed. Results indicated that faculty learning approach goals were positively associated with perceiving the shift to online teaching as a positive challenge and valuable for their competence development. Conversely, performance avoidance and work avoidance goals went along with perceiving this change as threatening, which was positively related to burnout levels and negatively related to student ratings of teaching quality.

Francescato highlighted a decade and half ago that online teaching could become as effective as face-to-face teaching [35]. Factors of faculty also play an essential role, particularly their goals and attitudes towards this sudden change. Given the right motivations and attitudes towards this transition, faculty may better handle such transitions and be equipped to acknowledge unexpected challenges such as the COVID-19 outbreak as opportunities instead of vexations.

\section{Acknowledgments}

We acknowledge the financial support from the City University of New York GRANT CCRG \# 1517, PSC-CUNY RESEARCH AWARD \# 62654-00 50, and CUNY RESEARCH SCHOLAR PROGRAM (2020- 
2021). We appreciate the mentee' students Fambougouri Diane, Daniel Bosah, Aissata Diop, and Paulin Dongomale for reading the manuscript and helping in editing. The contents of this paper are solely the responsibility of the author and do not represent the official views of the NIH.

\section{Author Contributions}

Eugene Mananga: Conceptualization, Writing - original draft, Writing - review \& editing. Lamisa Rusmeha: Writing - original draft, Writing - review \& editing.

\section{Competing Interests}

The authors have declared that no competing interests exist.

\section{Biography}

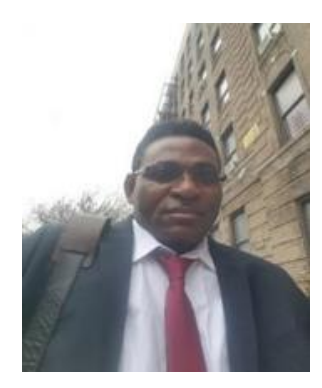

Dr Eugene Mananga is a Doctoral Faculty in Physics \& Chemistry Ph.D' Programs at the Graduate Center of the City University of New York (CUNY), where he is the recipient of the 2017 Henry Wasser Award in Physics, and the Program Director of STEM-Grants for the CUNY Academy for Humanities and Sciences. He is an Assistant Professor of Physics and Nuclear Medicine at Bronx Community College of CUNY and an Adjunct Professor of Applied Physics at New York University. Professor Mananga' s research and service efforts have been recognized by several awards including the 2018 Distinguished Scientist Award from the American Chemical Society (New York Section) for "Contributions and Advanced Studies in the Theory of Spin Dynamics in Solid-State Nuclear Magnetic Resonance and Quantum Mechanics", the 2018 PKAL STEM LEADERSHIP INSTITUTE II, the Laureate of 2017 Henry Wasser Award in Physics from the CUNY Academy of Humanities and Sciences in recognition of "Outstanding Scholarship and Academic Performance", and his scientific contribution in the field of Nuclear Magnetic Resonance was honored in the article dedicated to celebrate the 70th anniversary (1946 - 2016) of the Russian Academic of Sciences.

During the years 2021, 2020 and 2019, Dr. Mananga was selected to participate in the US Department of Energy Visiting Faculty Program at Lawrence Berkeley National Laboratory (Berkeley Lab, 2021 \& 2020) and at Argonne National Laboratory (University of Chicago, 2019) to work on problems related to energy storage and technology. Part of his current research interest is in the field of electrochemical energy storage with the focus on the characterization of the electrode materials for rechargeable batteries. Eugene completed his Ph. D in Physics from the City University of New York (with Distinguished Professor Steven Greenbaum, Hunter College) and holds 6 additional graduate degrees and training from various institutions including Harvard University, Massachusetts Institute of Technology (MIT), Massachusetts General Hospital (MGH), and City College of New York. Eugene did his postdoctoral studies in the National High Magnetic Field 
Laboratory of USA, Harvard Medical School and MGH. Prior to joining Harvard-MGH, Eugene was an "Ingenieur de Recherche" in the French Alternative Energies and Atomic Energy Commission (CEA-SACLAY, NEUROSPIN). Dr. Mananga current research interests include Condensed Matter Physics, Atomic and Molecular Physics, Nuclear Magnetic Resonance, Energy Materials, Medical Physics, Radiological Sciences and Nuclear Medicine. Currently, he is focused on advancing theory, simulation and methodology in Solid-State Nuclear Magnetic Resonance, Spin Dynamics, Quantum Physics, Imaging Science, Medical Physics and Nuclear Medicine.

Ms. Lamisa Rusmeha is an undergraduate student at Hunter College pursuing an Honors Specialization in Biochemistry \& Psychology. She recently joined Mananga's group and is working on the implementation of the SIMPSON software to simulate solid-state nuclear magnetic resonance experiments and its spectroscopic analogue.

\section{Reference}

1. Sharma A, Tiwari S, Deb MK, Marty JL. Severe acute respiratory syndrome coronavirus-2 (SARSCoV-2): A global pandemic and treatment strategies. Int J Antimicrob Agents. 2020; 56: 106054.

2. Pokhrel S, Chhetri R. A literature review on impact of COVID-19 pandemic on teaching and learning. High Educ Future. 2021; 8: 133-141.

3. Wikipedia. New York's 15th congressional district [Internet]. 2013. Available from: https://en.wikipedia.org/wiki/New York\%27s 15th congressional district.

4. SISK R. South Bronx: The poorest nationwide [Internet]. New York: Daily News; 2013. Available from: https://www.nydailynews.com/blogs/dc/south-bronx-poorest-nationwide-blog-entry1.1663594.

5. World Health Organization. WHO Director-General's opening remarks at the media briefing on COVID-19 - 11 March 2020 [Internet]. Genève: World Health Organization; 2020. Available from: https://www.who.int/director-general/speeches/detail/who-director-general-s-openingremarks-at-the-media-briefing-on-covid-19---11-march-2020.

6. National Center for Education Statistics. The Condition of Education 2019 [Internet]. Washington, DC: National Center for Education Statistics; 2019. Available from: https://nces.ed.gov/pubsearch/pubsinfo.asp?pubid=2019144.

7. Census Bureau. Suitland, MA: Census Bureau; 2019. Available from: https://www.census.gov/.

8. Mishra L, Gupta T, Shree A. Online teaching-learning in higher education during lockdown period of COVID-19 pandemic. Int J Educ Res Open. 2020; 1: 100012.

9. Aucejo EM, French J, Araya MP, Zafar B. The impact of COVID-19 on student experiences and expectations: Evidence from a survey. J Public Econ. 2020; 191: 104271.

10. United Nations. Education during COVID-19 and beyond [Internet]. Paris, France: The United Nations Educational, Scientific and Cultural Organization; 2020. Available from: https://www.un.org/development/desa/dspd/wpcontent/uploads/sites/22/2020/08/sg policy brief covid-

19 and education august 2020.pdf.

11. Thomson S, De Bortoli L, Nicholas M, Hillman K, Buckley S. Challenges for Australian education: Results from PISA 2009: The PISA 2009 assessment of students' reading, mathematical and scientific literacy. Camberwell, Australia: Australian Council for Educational Research; 2011. Available from: https://www.acer.org/files/PISA-Report-2009.pdf. 
12. Noble K, Hurley P, Macklin S. Number of Australia's vulnerable children is set to double as COVID-19 takes its toll [Internet]. Parkville: The Conversation; 2020. Available from: https://theconversation.com/number-of-australias-vulnerable-children-is-set-to-double-ascovid-19-takes-its-toll-140057.

13. Marteney T, Bernadowski C. Teachers' perceptions of the benefits of online instruction for students with special educational needs. Br J Spec Educ. 2016; 43: 178-194.

14. Paudel P. Online education: Benefits, challenges and strategies during and after COVID-19 in higher education. Int J Stud Educ. 2021; 3: 70-85.

15. Duraku ZH, Hoxha L. The impact of COVID-19 on education and on the well-being of teachers, parents, and students: Challenges related to remote (online) learning and opportunities for advancing the qualifications [Internet]. Available from: https://www.researchgate.net/publication/34129781.

16. Muthuprasad T, Aiswarya S, Aditya KS, Jha GK. Students' perception and preference for online education in India during COVID-19 pandemic. Soc Sci Humanit Open. 2021; 3: 100101.

17. Dung DT. The advantages and disadvantages of virtual learning. IOSR J Res Method Educ. 2020; 10: 45-48.

18. Hebebci MT, Bertiz Y, Alan S. Investigation of views of students and teachers on distance education practices during the Coronavirus (COVID-19) Pandemic. Int J Technol Educ Sci. 2020; 4: 267-282.

19. Serhan D. Transitioning from face-to-face to remote learning: Students' attitudes and perceptions of using zoom during COVID-19 pandemic. Int J Technol Educ Sci. 2020; 4: 335-342.

20. Pacheco JA. The "new normal" in education. Prospects. 2020. Doi: 10.1007/s11125-020-09521$x$.

21. Barbour MK, Reeves TC. The reality of virtual schools: A review of the literature. Comput Educ. 2009; 52: 402-416.

22. Chu Hui-Chun. Potential negative effects of mobile learning on students' learning achievement and cognitive load-a format assessment perspective. J Educ Techno Soc. 2014; 17: 332-344.

23. Unger S, Meiran WR. Student attitudes towards online education during the COVID-19 viral outbreak of 2020: Distance learning in a time of social distance. Int J Technol Educ Sci. 2020; 4: 256-266.

24. Rothstein J. The lost Generation? Labor Market Outcomes for Post Great Recession Entrants [Internet]. Available from: https://www.nber.org/papers/w27516.

25. Zhai Y, Du X. Mental health care for international Chinese students affected by the COVID-19 outbreak. Lancet Psychiat. 2020; 7: e22.

26. Alexander LM, Currie C. Young people's computer use: Implications for health education. Health Educ. 2004; 104: 254-261.

27. Saueressig IB, Xavier MK, Oliveira VM, Pitangui AC, Araújo RC. Primary headaches among adolescents and their association with excessive computer use. Rev Dor. 2015; 16: 244-248.

28. Oksanen A, Metsähonkala L, Anttila P, Aromaa M, Jäppilä E, Viander S, et al. Leisure activities in adolescents with headache. Acta Paediatr. 2005; 94: 609-615.

29. Auxier B, Anderson M. As schools close due to the coronavirus, some US students face a digital 'homework gap'. Pew Res Center. 2020; 16: 1-8.

30. Health Quality Ontario. Internet-delivered cognitive behavioural therapy for major depression and anxiety disorders: A health technology assessment. Ontario Health Technol Assess Ser. 2019; 
19: 1-199.

31. Peter C. Herman, online learning is not the future, June 10, 2020 [Internet]. Washington, DC: Inside Higher Ed; 2020. Available from: https://www.insidehighered.com/digitallearning/views/2020/06/10/online-learning-not-future-higher-education-opinion.

32. Asanov I, Flores F, McKenzie D, Mensmann M, Schulte M. Remote-learning, time-use, and mental health of Ecuadorian high-school students during the COVID-19 quarantine. World Dev. 2021; 138: 105225.

33. Al-Rabiaah A, Temsah MH, Al-Eyadhy AA, Hasan GM, Al-Zamil F, Al-Subaie S, et al. Middle East Respiratory Syndrome-Corona Virus (MERS-CoV) associated stress among medical students at a university teaching hospital in Saudi Arabia. J Infect Public Health. 2020; 13: 687-691.

34. Daumiller M, Rinas R, Hein J, Janke S, Dickhäuser O, Dresel M. Shifting from face-to-face to online teaching during COVID-19: The role of university faculty achievement goals for attitudes towards this sudden change, and their relevance for burnout/engagement and student evaluations of teaching quality. Comput Hum Behav. 2021; 118: 106677.

35. Francescato D, Porcelli R, Mebane M, Cuddetta M, Klobas J, Renzi P. Evaluation of the efficacy of collaborative learning in face-to-face and computer-supported university contexts. Comput Hum Behav. 2006; 22: 163-176.

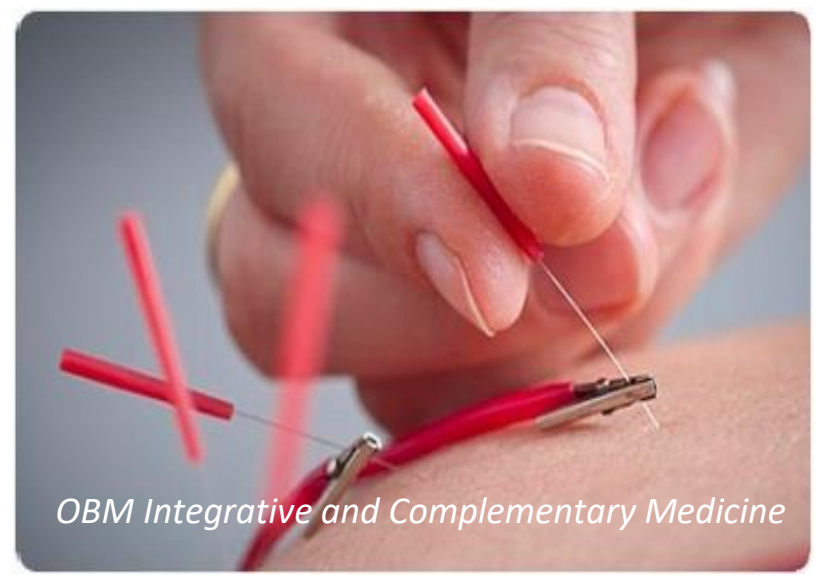

Enjoy $O B M$ Integrative and Complementary Medicine by:

1. Submitting a manuscript

2. Joining in volunteer reviewer bank

3. Joining Editorial Board

4. Guest editing a special issue

For more details, please visit: http://www.lidsen.com/journals/icm 